\title{
AN ASSESSMENT OF THE VALUE OF BREATHING EXERCISES IN CHRONIC BRONCHITIS AND ASTHMA
}

\author{
BY
}

\author{
R. S. McNEILL AND J. M. McKENZIE
}

From the Therapeutics Unit, Maryfield Hospital, Dundee, and the Department of Pharmacology and Therapeutics, University of St. Andrews

(RECEIVED FOR PUBLICATION MAY 17, 1955)

By tradition treatment by breathing exercises is well established in chronic lung disease, particularly where emphysema and bronchospasm are present. Weiser (1950) noted that it had its supporters amongst the Chinese in 2500 B.C. and later in classical and mediaeval times. It is not lacking supporters to-day, although in recent years some scepticism has been expressed about its effects. Donald (1953) in his review of respiratory function says that, although he has no evidence, he believes breathing exercises have no effect on emphysema and bronchospasm. Herxheimer (1952) agrees that in asthma much of the benefit claimed can be attributed to the psychological effects and he urges the necessity for objective tests. In addition, the work of Wade (1954) throws considerable doubt on the ability of individuals to control diaphragmatic movement at all in the act of breathing. This control is stressed by physiotherapists and is emphasized in the exercises recommended by the Asthma Research Council (1949).

The purpose of this study has been to try to assess the value of breathing exercises in chronic bronchitis and asthma. The yardstick has been a test of ventilatory efficiency which is the respiratory function that is most severely affected in these conditions. The maximum breathing capacity (M.B.C.) is a test with prestige, but we are in agreement with Kennedy (1953) in his claim that his measurement of the expiratory flow rate is more easily performed and repeated and he has found that it closely correlates with the M.B.C. $(r=0.93)$. In addition, Herxheimer (1952) remarked that sustained maximal breathing tends to increase bronchospasm, and this objection is less valid in the single forced expiration required in the measurement of the expiratory flow rate. Kennedy measured the expiratory flow rate in the first $\frac{3}{4}$-second period of a single forced expiration following full inspiration. He assumed that the inspiratory phase took a similar period of time and therefore the theoretical breathing rate was 40 breaths per minute. Thus, to express the expiratory flow rate in litres per minute he multiplied the volume expired in $\frac{3}{4}$ second by 40 . This figure is termed the E.F.R. ${ }_{40}$.

\section{METHOD}

Thirty-three patients were examined. All were seen as out-patients and were not in an acute phase of their illness. Each gave a history of recurrent attacks of asthma or bronchitis. They were examined clinically and radiologically and the dyspnoea grades were recorded according to the following criteria :

I. Undue dyspnoea on walking uphill or upstairs.

II. Undue dyspnoea on walking on the flat.

III. Dyspnoea at rest.

Table I gives the sex, age, diagnosis, and dyspnoea grade of each patient.

A spirometer was made to the specifications of Bernstein, D'Silva, and Mendel (1952) with a few $\stackrel{2}{x}$ modifications. The bell was made of celluloid which was slightly heavier than the thin aluminium sheet 3 metal advised. The inlet to the bell was $2.5 \mathrm{~cm}$. in diameter. A kymograph moving at $1.65 \mathrm{~cm}$. $/ \mathrm{sec}$. was used to record the expiratory vital spirogram. The E.F.R.40 when recorded was the average of six tracings. $\frac{3}{7}$ It was obtained for all patients, except one, on three $\frac{7}{0}$ to five occasions in the two weeks preceding and in the two weeks following a period of treatment by $N$ breathing exercises. One case, No. 9, had only two 0 readings before treatment and one after. As a control $N$ group five female and five male patients were selected $N$ at random. This group received graduated doses of $\frac{\mathrm{W}}{\sigma}$ ultra-violet light twice weekly for one month as a suitably impressive but neutral form of treatment. The remaining 23 patients were started on breathing $\mathbb{\Phi}$ exercises and instruction was given twice weekly by a physiotherapist for a total of eight lessons. The 7 patients were instructed to carry out these exercises $\stackrel{0}{\circ}$ twice daily at home. The exercises taught were those $\mathbb{Q}$ recommended by the Asthma Research Council (1949). Nine of the patients completed their course in one 
TABLE I

CLINICAL DETAILS OF THE SERIES

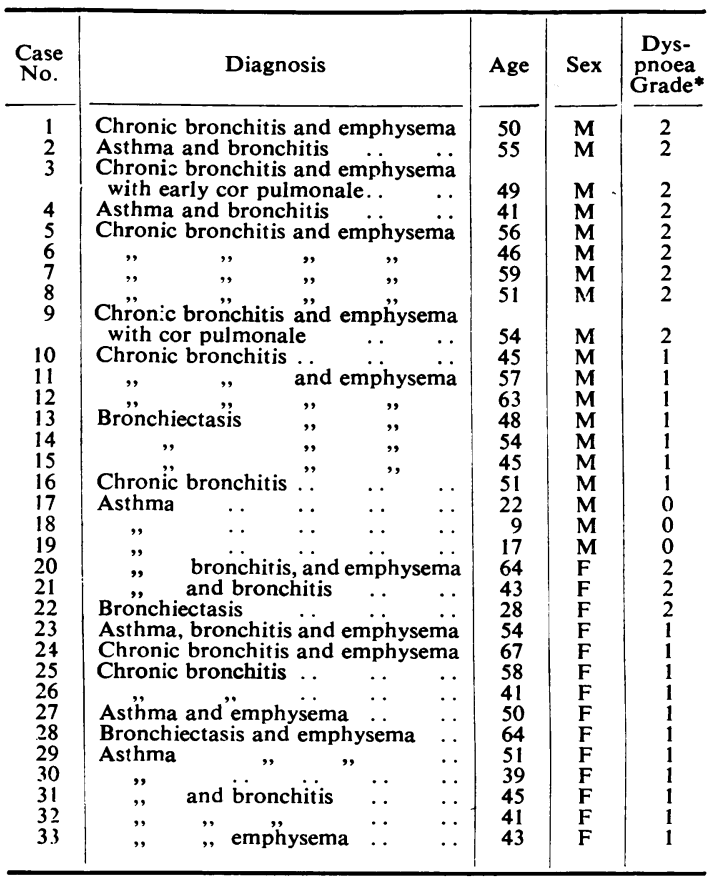

* = Dyspnoea grades as described in text.

month, seven in two months, and one had exercises sporadically over three months. Six patients did not complete the course. Of the 10 patients receiving ultra-violet light, eight completed the course within one month and two failed to complete the course at all.

Treatment was started immediately after the last pre-treatment E.F.R.40 reading was obtained. The first E.F.R.40 after treatment was obtained on the day that the course ended.

\section{RESULTS}

Of the 17 patients who completed the course of breathing exercises there was an improvement in the average E.F.R. ${ }_{40}$ in 11 and a deterioration in six. The mean improvement and deterioration were both $15 \%$. The mean improvement for the group as a whole was $4 \%$, and this increase is not statistically significant. Of the six patients who failed to complete the course of exercises two are known to have had an acute exacerbation of their chest condition and required admission to hospital. Why the remaining four patients defaulted is not known.

Three of the eight patients who completed the course of treatment with ultra-violet light showed an improvement in the average E.F.R..$_{40}$. Four deteriorated and in one there was no change. There was a mean deterioration for these eight patients of $2 \%$. Two patients failed to complete the course, one because of a relapse necessitating admission to hospital and the other defaulted for an unknown reason.

\section{Discussion}

There is little objective evidence for the value of breathing exercises. Weiser (1950) and Nelson (1953) refer to the vital capacity in discussing breathing exercises, but there is considerable objection to this as a measure of ventilatory efficiency, as the time required for a complete expiration is not taken into account. However, Briscoe and McLemore (1952) suggest that it may be of more value in measuring improvement due to the relief of bronchospasm. Fein, Cox, and Green (1953) have also used hemithorax measurements in assessing the value of exercises in asthma. Recently, Campbell and Friend (1955) have shown, using lung volumes, mixing efficiency, and the M.B.C. as tests of ventilatory function, that breathing exercises had no effect in 12 emphysematous patients over a three-month period.

TABLE II

RESULTS $O \bar{F}$ TREATMENT

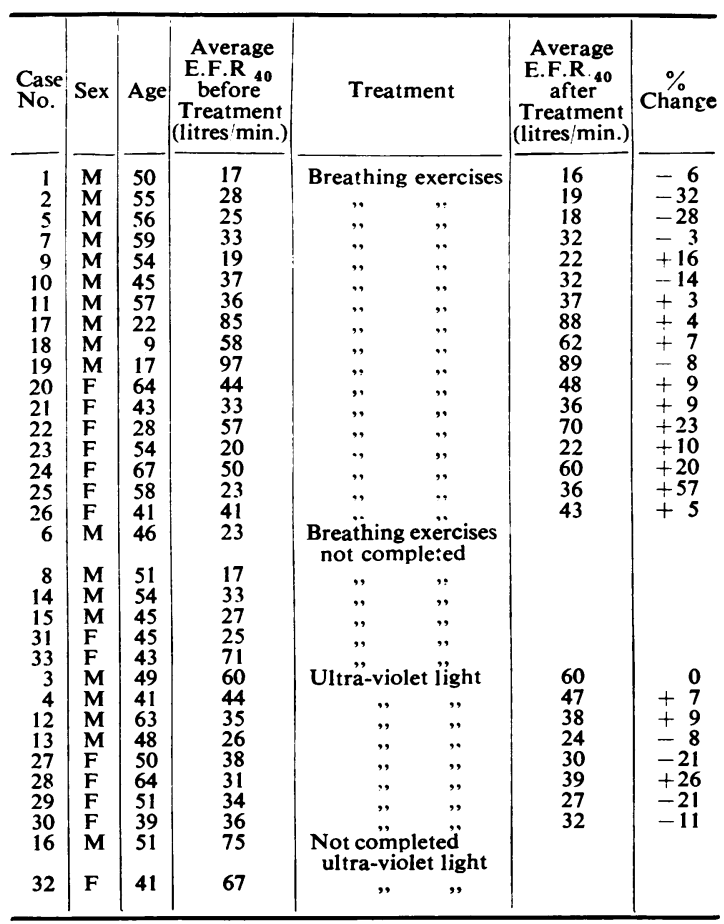


The patients we have studied all had bronchospasm, emphysema, or both, causing impaired ventilatory efficiency. They represent a crosssection of the out-patients commonly referred for breathing exercises. We were impressed by the frequency with which patients failed to attend for treatment and there is an obvious discrepancy in many cases between the treatment ordered by the physician and that received by the patient. Patients presumably default in their treatment because they are worse and too ill to attend or because they do not consider that the treatment is helping. We have not included in our results those patients who failed to complete the course of treatment although they might well be judged to have derived no benefit.

Friend (1954) has shown a seasonal variation in pulmonary function tests, with an improvement in the summer months, in patients suffering from emphysema. The present study was carried out between January and September, 1954, and we were unable to find that improvement occurring in either treatment or control group was related to the beginning of summer.

From the numbers involved it is not possible to say that in this type of patient breathing exercises are valueless, but it certainly seems unlikely that benefit will be shown to be appreciable and worth while.

\section{SUMmary}

An attempt has been made to assess the value of breathing exercises in chronic bronchitis and asthma using the E.F.R. ${ }_{40}$ as a measure of ventilatory efficiency of the lungs before and after treatment.

Twenty-three patients started on breathing exercises and 17 of these completed the course. As shown by the E.F.R. ${ }_{40}, 11$ improved and six deteriorated. The mean improvement for the group was $4 \%$. This is not a statistically significant figure. Furthermore, the six patients who did not complete the course of breathing exercises might fairly be considered to have derived no benefit from them.

A control group of 10 patients was given ultraviolet light irradiation. Two of this group failed to complete the course. Four patients deteriorated, three improved, and in one there was no change. The mean deterioration for the group was $2 \%$.

The numbers involved do not enable us to say that breathing exercises are of no value in asthma and bronchitis, but it is unlikely that any larger series would show appreciable and worth-while benefit from this therapy.

We wish to thank Professor R. B. Hunter, in whose department this work was done, for help and advice ; Professor W. Melville Arnott for helpful criticism of the original draft; Dr. T. Sprunt for reporting on the radiographs; and Miss $D$. Smith and her staff in the physiotherapy department of Maryfield Hospital for valuable assistance.

\section{REFERENCES}

Asthma Research Council (1949). Physical Exercises for Asthma 8th ed. Asthma Research Council, London.

Bernstein, L., D'Silva, J. L., and Mendel, D. (1952). Thorax, 7, 255. Briscoe, W. A., and McLemore, G. A., Jr. (1952). Ibid., 7, 66.

Campbell, E. J. M., and Friend, J. (1955). Lancet, 1, 325.

Donald, K. W. (1953). Brit. med. J., 1, 415.

Fein, B. T., Cox., E. P., and Green, L. H. (1953). Ann. Allergy, 11, 275.

Friend, J. (1954). Clin. Sci., 13, 491.

Herxheimer, H. (1952). Brit. J. phys. Med., 15, 129.

Kennedy, M. C. S. (1953). Thorax, 8, 73.

Nelson, P. A. (1953). Cleveland Clin. Quart., 20, 269

Wade, O. L. (1954). J. Physiol., Lond., 124, 193.

Weiser, H. I. (1950). Brit. J. phys. Med., 13, 127. 